\title{
Excimer retreatment for scarring and regression after photorefractive keratectomy for myopia
}

\author{
Gerard Sutton, Richard S Kalski, Michael A Lawless, Christopher Rogers
}

\begin{abstract}
Aims/Background-Scarring associated with regression of refractive effect can occur after photorefractive keratectomy (PRK) for myopia. The experience of treating these complications is reported. Methods-Eighteen of 285 eyes $(6 \cdot 3 \%)$ were retreated with the excimer laser. Age, sex, preoperative primary treatment keratometry, pre-primary treatment, pre-retreatment and post-retreatment spherical equivalents, best corrected and uncorrected visual acuities were recorded and analysed.
\end{abstract}

Results-At 6 months post-retreatment, the mean spherical equivalent was -2.07 equivalent persisted in eyes followed for 12 months (-2.85D, SD 4.09 D). Nine of 18 eyes $(50 \%)$ had uncorrected visual acuity of $6 / 12(20 / 40)$ or better. If retreatment was undertaken within 6.5 months of the initial PRK, then scarring was likely to recur $(p=0.035)$. Nine of 10 eyes $(90 \%)$ which had a retreatment spherical equivalent less than two thirds of their primary treatment spherical equivalent were within plus or minus $1 \cdot 25 D$ from emmetropia after retreatment. Four of 11 eyes $(36 \%)$ followed for 12 months after retreatment rescarred with further regression.

Conclusion-The data showed that eyes with scarring and regression of myopia should not be treated with PRK within 6 months of the initial procedure. Eyes with the highest percentage of regression towards their initial myopia tend to have a poor response to retreatment.

(Br f Ophthalmol 1995; 79: 756-759)

Scarring and regression are serious complications of excimer laser photorefractive keratectomy (PRK) to correct myopia. The correction of high myopia is associated with an increased incidence of these complications. ${ }^{1-5}$ Retreatment with a further photoablative procedure for these complications has been reported. 56 We present the results of 18 eyes with scarring and regression after PRK that have been retreated.

Surgery Centre,

St Leonards, New South Wales, Australia G Sutton

R S Kalski

M A Lawless

C Rogers

Correspondence to:

Christopher Rogers

66 Pacific Highway,

St Leonards, NSW 2065 , Australia.

Accepted for publication 24 April 1995 Subjects and methods

The 18 eyes in this study represent a subgroup of 285 eyes which had PRK with a Summit ExciMed laser using a $5 \mathrm{~mm}$ ablation zone with a minimum follow up of 12 months. Twenty one eyes $(7 \cdot 4 \%)$ of this treatment dioptres (D) (SD 4.60 D). This spherical

group have demonstrated scarring and regression. Nineteen eyes have been retreated. One eye was lost to follow up. Of the remaining 18 eyes $(6.3 \%)$, four had a pre-primary treatment spherical equivalent between -1.00 and -6.00 dioptres (D) (mean $-5.31 \mathrm{D}$, SD $0 \cdot 446 \mathrm{D}$ ), eight eyes were between $-6 \cdot 10 \mathrm{D}$ and $-10 \cdot 00 \mathrm{D}$ (mean $-7 \cdot 75 \mathrm{D}$, SD $1 \cdot 18 \mathrm{D}$ ), and six eyes had $-10 \cdot 10 \mathrm{D}$ or more of myopia (mean $-13 \cdot 6 \mathrm{D}$, SD 1.89D). Ten eyes were from five patients. Age, sex, preoperative primary treatment keratometry, pre-primary treatment, preretreatment, and post-retreatment spherical equivalents, and best corrected and uncorrected visual acuities were recorded and analysed.

A Summit Technology ExciMed UV200 excimer laser (Waltham, MA, USA) was used for the primary treatment and retreatment in all 18 eyes. All 18 eyes had subepithelial scarring, with loss of corneal transparency and regression of myopia.

The preoperative primary treatment data are listed in Table 1 . The mean age was $39 \cdot 1$ (SD $12 \cdot 1)$ years. The age range was 23 to 63 years. The population consisted of 11 eyes from men and seven eyes from women. Treatment goal was a refraction of plano. Eyes were treated by two surgeons (MAL and CR) who followed the same protocol.

Before excimer laser retreatment PRK, one drop of pilocarpine $2 \%$ and several drops of amethocaine $1 \%$ were instilled in the preoperative eye. The lids were opened using a light wire speculum and the epithelium was removed using phototherapeutic keratectomy (PTK). It is difficult to debride the corneal epithelium manually and to judge the end point of epithelial removal. For the first two eyes, epithelial removal was performed as reported by Seiler et $a l,{ }^{5}$ ceasing PTK when the fluorescence changed from a blue hue to black in a peripheral, concentric, confluent ring. However, this was found to be a difficult technique. The subsequent 16 eyes underwent epithelial removal using a 150 pulse PTK with a $5 \mathrm{~mm}$ ablation zone. Methylcellulose was not used. The PRK retreatment was then performed. Calculation of the amount of PRK was based on the eye's refraction converted to the central corneal plane plus $-1 \mathrm{D}$ to compensate for the central epithelium not being totally removed by the PTK.

After retreatment, cyclopentolate $1 \%$ and tobramycin $0.3 \%$ eyedrops were instilled. A semi-pressure patch was applied for 3 days. All patients had re-epithelialised within 72 hours. Once re-epithelialisation had occurred, patients were commenced on dexamethasone 
Table 1 Clinical data

\begin{tabular}{|c|c|c|c|c|c|c|c|c|c|c|c|}
\hline Eye & Age & Sex & $\begin{array}{l}\text { Follow up } \\
\text { (months) }\end{array}$ & $\begin{array}{l}\text { Preoperative } \\
A K\end{array}$ & $\begin{array}{l}\text { Pre-primary } \\
\text { treatment } S E\end{array}$ & $\begin{array}{l}\text { Pre-retreatment } \\
S E\end{array}$ & $\begin{array}{l}\text { Post retreatment } \\
S E\end{array}$ & $\begin{array}{l}\text { Pre-primary } \\
\text { treatment } B C V A\end{array}$ & $\begin{array}{l}\text { Pre-retreatment } \\
B C V A\end{array}$ & $\begin{array}{l}\text { Post retreatment } \\
\text { BCVA }\end{array}$ & $\begin{array}{l}\text { Post retreatment } \\
\text { UCVA }\end{array}$ \\
\hline $\begin{array}{r}1 \\
2 \\
3 \\
4 \\
5 \\
6 \\
7 \\
8 \\
9 \\
10 \\
11 \\
12 \\
13 \\
14 \\
15 \\
16 \\
17 \\
18\end{array}$ & $\begin{array}{l}29 \\
38 \\
32 \\
36 \cdot 7 \\
36 \cdot 7 \\
23 \cdot 2 \\
59 \\
54 \\
30 \cdot 7 \\
30 \cdot 7 \\
63 \\
50 \\
23 \\
32 \\
36 \\
50 \\
54 \\
32\end{array}$ & $\begin{array}{l}F \\
F \\
F \\
M \\
M \\
F \\
M \\
M \\
M \\
M \\
M \\
F \\
M \\
M \\
F \\
F \\
M \\
M\end{array}$ & $\begin{array}{r}6 \\
6 \\
6 \\
12 \\
12 \\
12 \\
12 \\
12 \\
12 \\
12 \\
6 \\
6 \\
6 \\
6 \\
12 \\
12 \\
12 \\
12\end{array}$ & $\begin{array}{l}40 \cdot 12 \\
43 \cdot 87 \\
43 \cdot 87 \\
46 \cdot 00 \\
45 \cdot 75 \\
43 \cdot 25 \\
43 \cdot 62 \\
41 \cdot 25 \\
44 \cdot 25 \\
44 \cdot 25 \\
42 \cdot 25 \\
45 \cdot 38 \\
42 \cdot 87 \\
42 \cdot 50 \\
43 \cdot 75 \\
44 \cdot 25 \\
41 \cdot 50 \\
42 \cdot 75\end{array}$ & $\begin{array}{r}-4 \cdot 75 \\
-6 \cdot 25 \\
-8 \cdot 00 \\
-5 \cdot 25 \\
-5 \cdot 25 \\
-6 \cdot 00 \\
-6 \cdot 13 \\
-11 \cdot 88 \\
-12.50 \\
-12.75 \\
-8 \cdot 12 \\
-9 \cdot 25 \\
-9.50 \\
-17 \cdot 13 \\
-6 \cdot 88 \\
-7 \cdot 88 \\
-12 \cdot 13 \\
-15.00\end{array}$ & $\begin{array}{r}-1.50 \\
-3.00 \\
-4.75 \\
-2.50 \\
-3.00 \\
-2.25 \\
-3.88 \\
-4.50 \\
-3.25 \\
-3.00 \\
-5.87 \\
-8.50 \\
-9.75 \\
-16.00 \\
-8.00 \\
-7.88 \\
-11.00 \\
-10.25\end{array}$ & $\begin{array}{r}-1.25 \\
+0.87 \\
0.00 \\
0.00 \\
0.00 \\
0.00 \\
-0.25 \\
0.00 \\
-4.50 \\
+1.25 \\
-6.25 \\
-1.00 \\
+1.00 \\
-14.00 \\
-6.25 \\
-8.00 \\
-2.37 \\
-11.25\end{array}$ & $\begin{array}{l}6 / 9 \\
6 / 6 \\
6 / 6 \\
6 / 6 \\
6 / 6 \\
6 / 6 \\
6 / 9 \\
6 / 6 \\
6 / 9 \\
6 / 12 \\
6 / 6 \\
6 / 6 \\
6 / 9 \\
6 / 18 \\
6 / 6 \\
6 / 6 \\
6 / 6 \\
6 / 12\end{array}$ & $\begin{array}{l}6 / 6 \\
6 / 9 \\
6 / 6 \\
6 / 6 \\
6 / 6 \\
6 / 6 \\
6 / 6 \\
6 / 12 \\
6 / 9 \\
6 / 12 \\
6 / 24 \\
6 / 18 \\
6 / 24 \\
6 / 36 \\
6 / 6 \\
6 / 12 \\
6 / 24 \\
6 / 12\end{array}$ & $\begin{array}{l}6 / 6 \\
6 / 6 \\
6 / 9 \\
6 / 6 \\
6 / 6 \\
6 / 6 \\
6 / 6 \\
6 / 9 \\
6 / 18 \\
6 / 9 \\
6 / 6 \\
6 / 12 \\
6 / 9 \\
6 / 18 \\
6 / 6 \\
6 / 12 \\
6 / 6 \\
6 / 12\end{array}$ & $\begin{array}{l}6 / 18 \\
6 / 12 \\
6 / 9 \\
6 / 6 \\
6 / 6 \\
6 / 6 \\
6 / 18 \\
6 / 9 \\
\text { CF } \\
6 / 12 \\
\text { CF } \\
6 / 12 \\
6 / 9 \\
\text { CF } \\
\text { CF } \\
\text { CF } \\
6 / 24 \\
\text { CF }\end{array}$ \\
\hline
\end{tabular}

$\mathrm{AK}=$ average keratometry; $\mathrm{SE}=$ spherical equivalent; $\mathrm{BCVA}=$ best corrected visual acuity; $\mathrm{UCVA}=$ uncorrected visual acuity; $\mathrm{CF}=$ count fingers.

$0 \cdot 1 \%$ drops three times a day. This dose was decreased by one drop per month until it was discontinued completely after 3 months. The scar was always removed satisfactorily, as judged by slit-lamp examination.

\section{Results}

The mean spherical equivalent before primary treatment PRK was -9.32D (SD 3.61D). Before retreatment, the mean spherical equivalent was $-6.05(3.91) \mathrm{D}$, ranging from $-1.50 \mathrm{D}$ to $-16.00 \mathrm{D}$. At 6 months postretreatment, the mean spherical equivalent had decreased to $-2 \cdot 07(4 \cdot 60) \mathrm{D}$. This reduction in spherical equivalent persisted in the 11 eyes followed to the 12 month follow up period, at which time the mean spherical equivalent was $-2 \cdot 85(4 \cdot 09) \mathrm{D}$. Pre-primary treatment, pre-retreatment, and post-retreatment spherical equivalent refractions, and best corrected and uncorrected visual acuities are listed in Table 1 . The best corrected visual acuity was $6 / 12(20 / 40)$ or better in 16 eyes $(89 \%)$ after retreatment (Table 1$)$. However, five eyes $(28 \%)$ had lost best corrected acuity when compared with their pre-primary treatment best corrected visual acuity. Three eyes $(17 \%)$ had improved best corrected visual

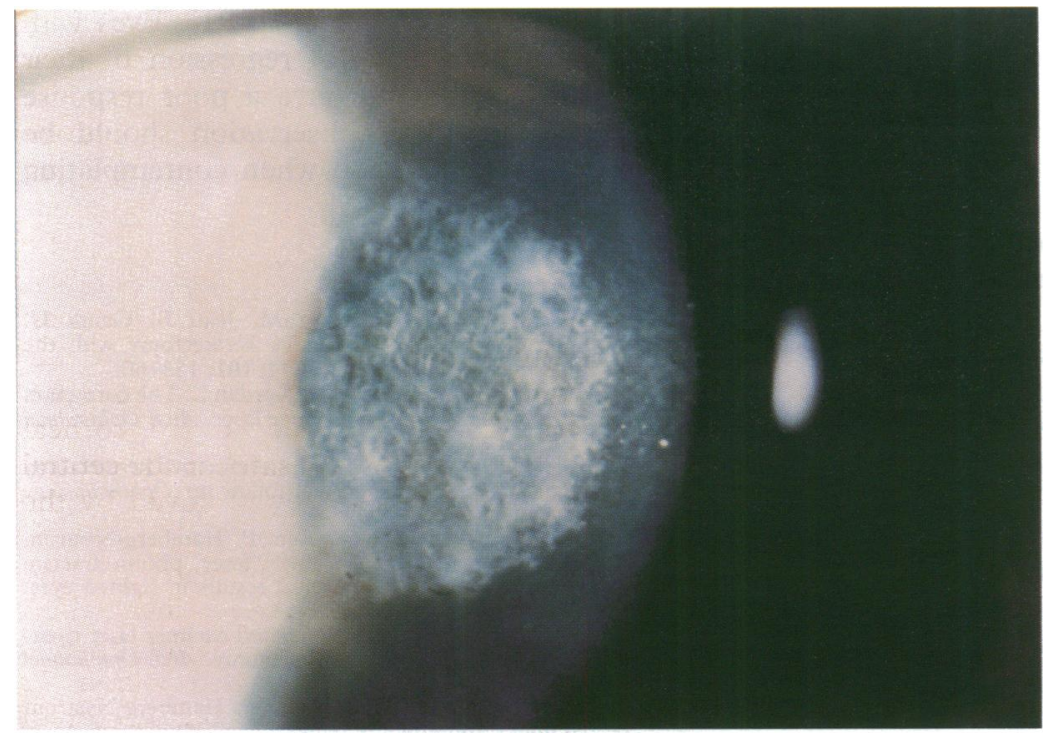

Figure 1 Scarring associated with myopic regression. acuity. Nine of 18 eyes $(50 \%)$ had uncorrected visual acuity of $6 / 12$ or better. Of the 11 eyes followed for 12 months after retreatment, four $(36 \%)$ have rescarred with associated further regression. The mean time from primary treatment to retreatment was 10.54 (4.07) months with a range of 4-18 months. If retreatment was undertaken within 6.5 months of the initial PRK, then scarring was likely to recur $(p=0.035)$.

Further data analysis revealed that eyes which had a pre-retreatment spherical equivalent less than two thirds $(67 \%)$ of their pre-primary treatment spherical equivalent had a mean post-retreatment spherical equivalent of $-0.388(1.59) \mathrm{D}$ (Table 1 , eyes $1-10)$. Only one eye had greater than $1 \cdot 25 \mathrm{D}$ from emmetropia. The remaining eight eyes with a pre-retreatment spherical equivalent greater than two thirds of their pre-primary treatment spherical equivalent (mean 92\%) had a mean post-retreatment spherical equivalent of $-6.02(5 \cdot 11) \mathrm{D}$ (Table 1 , eyes 11-18). Only two eyes were within $1 \cdot 25 \mathrm{D}$ of emmetropia. The four eyes with rescarring were in this subgroup.

\section{Discussion}

In the majority of postoperative PRK patients, a minimal loss of corneal clarity, or mild haze, was observed. Haze onset in humans occur at about 2 weeks to 1 month post-PRK, slowly increases, and then decreases in most eyes by between 12 and 24 month after PRK. ${ }^{7}$ These observations are considered to be a part of the normal healing response of the cornea after PRK, and eyes that experience this response achieve and maintain a good postoperative refraction. A small group of eyes have scarring, or marked haze, in their postoperative course (Fig 1). This post-PRK response results in myopic regression. A histopathological study by Lohmann $e a^{8}$ confirmed that corneal tissue in these individuals showed an aggressive healing response, rich in new extracellular matrix, but sparse in newly synthesised collagen.

The predictability and efficacy of PRK tends to decrease in higher corrections. ${ }^{39-11}$ Corneal scarring, or severe haze, with regression of refractive effect increases in high myopia. ${ }^{1-5} 12$ 
It is unclear if this observation is secondary to the attempted correction or ablation zone diameter and shape. Sher and colleagues ${ }^{13}$ reported good refractive results and minimal regression using ablation zone diameters between $5.5 \mathrm{~mm}$ and $6 \mathrm{~mm}$ in eyes with spherical equivalents between 8.6 and $14.5 \mathrm{D}$ of myopia. We have had promising results using a multizone technique in high myopia with ablation zone diameters between $5.5 \mathrm{~mm}$ and $6.5 \mathrm{~mm}$ (unpublished data). In this report, 21 of 285 eyes $(7 \cdot 4 \%)$ had scarring and regression using a $5 \mathrm{~mm}$ ablation zone.

Other investigators have reported their results regarding retreatment for regression with or without corneal scarring after PRK. Heitzmann and associates ${ }^{2}$ retreated two of 23 eyes $(8 \cdot 7 \%)$ for haze and regression with preprimary treatment spherical equivalents of -11.00 and $-13.50 \mathrm{D}$. Seiler et al ${ }^{1}$ retreated 27 of 193 eyes (14\%) for regression, $10(5 \%)$ of which had scarring. Scarring and regression were dependent on attempted correction. In a separate study, Seiler et $a l^{5}$ noted scarring in $1.8 \%$ of 298 patients with less than $6 \mathrm{D}$ of myopia and in $8.8 \%$ with greater than $6.1 \mathrm{D}$ of myopia. Undercorrection of $1 \mathrm{D}$ or more was noted in $2.7 \%$ of eyes with less than $6 \mathrm{D}$ of myopia initially, $36.9 \%$ of eyes with initial myopia of $-6 \cdot 25$ to $-10 \mathrm{D}$, and $42 \cdot 8 \%$ of eyes with greater than $-10 \cdot 1 \mathrm{D}$ of myopia. Sixty three per cent of 30 retreated eyes had a manifest refraction between plus or minus 1D 6 months after retreatment with only one eye showing mild scar formation. Epstein et $a l^{6}$ reported on 17 eyes retreated for regression without corneal scarring. Six months after retreatment, $58.8 \%$ were within plus or minus $1 \mathrm{D}$ of emmetropia and $64.7 \%$ had an uncorrected visual acuity greater than or equal to $6 / 12(20 / 40)$. In this study of regression with scarring, we report similar findings. Nine of 18 eyes $(50 \%)$ had uncorrected visual acuity of $6 / 12(20 / 40)$ or better. However four eyes rescarred and had associated regression of refractive effect. We also noted that eyes with the highest percentage regression of their initial myopia tend to do equally poorly after retreatment. Nine of 10 eyes $(90 \%)$ with a preretreatment spherical equivalent less than two thirds of their pre-primary treatment spherical equivalent were within $1 \cdot 25 \mathrm{D}$ of emmetropia. This is in sharp contrast with two of eight eyes $(25 \%)$ within this range when the pre-retreatment spherical equivalent was greater than two thirds of their pre-primary treatment spherical equivalent. The four eyes that rescarred were within this subgroup.

We found a positive correlation between a short period to retreatment and the incidence of further scarring. This finding confirms Lohmann et als observation that eyes retreated shortly after the primary PRK would not have completed their original wound healing response. ${ }^{8} \mathrm{~A}$ further aggressive reaction manifested as rescarring was stimulated in these eyes.

Tengroth $e t$ al $^{4}$ suggest that topical steroids reverse regression after PRK. In a preliminary report from our centre regarding retreatment of undercorrected myopia, we found the eyes involved in this study to be unresponsive to topical steroids. ${ }^{14}$ Results from Lohmann and associates' histopathological study of $\mathrm{PRK}^{8}$ suggest that in high regression but low haze, a reduced refractive effect may be secondary to epithelial hyperplasia alone. Refraction may be corrected solely by mechanical debridement of the epithelium in these eyes, but the long term refractive effect is not known. In eyes with high regression and high haze, both the epithelium and underlying tissue show a wound healing response. Mechanical debridement alone could possibly remove both involved corneal layers, but a retreatment PRK may be more appropriate in treating the aggressive wound healing response. However, re-lasering these corneal layers initiates a second period of wound healing in the stroma. This response may explain why four of the 11 eyes followed for 12 months rescarred after retreatment. Individual healing response also has an apparent role. In the 18 retreated eyes reported in this study, 10 eyes were from five patients. The second eye mirrored the first in its behaviour.

As the number of excimer laser procedures performed increases, the number of potential complications correspondingly increases. Complications should decrease as our understanding of treatment strategies increases with further improvements and refinements in techniques and laser technology. We can extrapolate clinical strategies from our data when considering retreating scarring with associated regression after PRK. A positive correlation was found between a short period to retreatment and the incidence of further regression and scarring. We confirm Lohmann et al's recommendation $^{8}$ not to re-operate earlier than 6 months under these circumstances. It is now our practice not to reoperate for at least 12 months. If a first eye shows significant scarring with regression, PRK on the second eye may mimic this response. If significant scarring is noted early in the postoperative course, it may be prudent to observe the response over time before making a decision about performing PRK on the fellow eye. To date, there is no way to predict which eyes will have an aggressive healing response before PRK. Eyes with the highest percentage of regression of their initial myopia tend to have a poor response to retreatment. This observation should be taken into consideration when contemplating retreatment.

1 Seiler T, Holshbach A, Derse M, Jean B, Genth U. Complications of photorefractive keratectomy with the Complications of photorefractive keratectomy with
excimer laser. Ophthalmology 1994; 101: 153-60.

2 Heitzmann J, Binder P, Kassar B, Nordan L. The correction of high myopia using the excimer laser. Arch Ophthalmol 1993; 111: 1627-34.

3 Seiler T, Wollensak J. Myopic photorefractive keratectomy with the excimer laser. One year follow up. Ophthalmology 1991; 98: 1156-63.

4 Tengroth B, Epstein D, Fagerholm P, Hamberg-Nystrom H, Fitzsimmons TD. Excimer laser photorefractive keratectomy for myopia. Clinical results in sighted eyes. Ophthalmology 1993; 100: 739-45.

5 Seiler T, Derse M, Pham T. Repeated excimer laser treatment after photorefractive keratectomy. Arch Ophthalmol 1992; 110: 1230-3.

6 Epstein D, Tengroth B, Fagerholm P, Hamberg-Nystrom H. Excimer retreatment of regression after photorefractive keratectomy. Am $¥$ Ophthalmol 1994; 117: 456-61. 
7 Lohmann C, Gartry D, Kerr Muir M, Timberlake G, Fitzke F, Marshall J. "Haze" in photorefractive keratectomy: its origins and consequences. Laser Light Ophthalmology $1991 ; 4: 15-34$

8 Lohmann CP, MacRobert I, Patmore A, O'Brart D Corbett M, Kerr Muir M, et al. A histopathological study of photorefractive keratectomy. Laser Light Ophthalmol 1991; 6: 149-58.

9 Gartry DS, Kerr Muir M, Marshall J. Photorefractive keratectomy with an argon fluoride laser: a clinical study. Refract Corneal Surg 1991; 7: 420-35.

10 McDonald MB, Liu JC, Byrd TJ, Abdelmegeed M, Angotti Andrade $\mathrm{H}$, Klyce SD, et al. Central photorefractive keratectomy for myopia: partially sighted and normally keratectomy for myopia: partially sighted and
sighted eyes. Ophthalmology 1991; 98: 1327-38.
11 Sher NA, Chen V, Bowers RA, Frantz JM, Brown DC, Eiferman $\mathrm{R}$, et al. The use of the 193-nm excimer laser for myopic photorefractive keratectomy in sighted eyes: a multicenter study. Arch Ophthalmol 1991; 109 1525-30.

12 Gartry DS, Kerr Muir M, Marshall J. Excimer laser photorefractive keratectomy: eighteen month follow up. Ophthalmology 1992; 99: 1209-19.

13 Sher NA, Barak M, Sheraz D, DeMarchi J, Tucci A Hardten DR, et al. Excimer laser photorefractive keratectomy in high myopia. A multicenter study. Arch Ophthalmol 1992; 110: 935-43.

14 Lawless MA, Cohen PR, Rogers CM. Retreatment of undercorrected photorefractive keratectomy for myopia. Refract Corneal Surg 1994; 10 (Suppl): S174-7. 